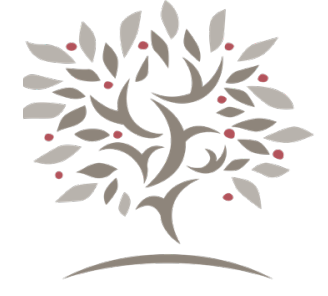

\title{
Advocacy for Teaching Mindfulness Practices and World Religions in Public Schools
}

\author{
Trung Huynh (Thich Hang Dat) \\ University of Houston
}

\begin{abstract}
A B S TRACT
People from various walks of life, professions, and traditions, including Christians, have been implementing mindfulness practices as cost-effective tools to deal with physical and mental health issues. Notably, numerous studies have demonstrated that mindfulness training has brought tremendous benefits to K-12 students, both physiologically and psychologically. As a result, this training should be implemented in public schools for the sake of our children's well-being, behavior, mental health, and educational success. Some states, such as Texas and Kentucky, have given the Christian Bible priority and teach it in schools while excluding other traditions and sacred texts. This precedent, however, violates the First Amendment. Public schools in this modern globalized era should instead provide teachers proper training and knowledge so they can teach their students broader perspectives on world religions, including Western and Eastern traditions.
\end{abstract}

\section{KEYWORDS}

mindfulness, world religions, public schools, K-12, eastern tradition, Bible, First Amendment.

\section{Introduction}

After more than four decades of scientific evidence, mindfulness-based practices, which are rooted in religious traditions, especially Buddhism, but which have been stripped of their religious notions, are widely used. In school settings mindfulness-based practices help students deal with stress, anxiety, depression, attention deficit disorder, behavior issues, general function, executive disfunction, and impart learning skills that improve their educational achievements. Therefore, school districts around the country should provide training and tools for teachers to use cost-effective mindfulness interventions when they teach world religions to help students with their physiological and psychological health issues and so students understand broader religious perspectives that can better prepare them to become global citizens. 
Children's learning, behavior, and overall health may be compromised by excessive stress. Other influences-familysystem disturbances, peer-interaction conflicts, sociocultural components, and vulnerabilities to physical and mental health risk factors-can create toxic stress. To address these mental health issues and to enhance students' academic achievements, mindfulness practice is considered the most cost-effective tool.

Throughout history, many civilizations have practiced mindfulness meditation for spiritual and well-being purposes (Braboszcz and Arnaud 1910). Buddhist mindfulness meditation, one of the religion's core teachings and practices, was preserved and gained popularity in the modern age through a secular style that has stripped of its Buddhist textual and descriptive roots.

Mindfulness is described as a mental state and a set of practices, made up of two constituents: one, the attentive selfregulation that sustains immediate experience and increases the recognition of mental events in the present moment, and two, the adoption of an approach to experiences in the current moment based on curiosity, openness, and acceptance (Suárez-García et al. 2020).

Contemporary mindfulness excludes Buddhist notions of ethics, judgment, and memory. Specifically, while promoting the universal principles (which include Buddhist theory) of loving kindness and compassion, contemporary mindfulness removes strict and instituted Buddhist moral guidelines, specific vows, and certain orthodox frameworks which then allows practitioners to set their own ethical standards. Contemporary mindfulness also implements a nonjudgmental attitude by not evaluating the mental state as something to be cultivated or discarded, as advocated by classical Buddhism. It also does not utilize Buddhist terminology to examine the mental state. For instance, in contemporary mindfulness, practitioners are supposed to recognize their distractions and return to their focus object without employing any mental manipulation or using any morally charged judgments. In classical Buddhist mindfulness, practitioners are supposed to "recollect" or "keep in mind" their spiritual goals, ethics, or vows (such as various mental states that need to be cultivated or rejected) without dwelling on past occurrences or future engagements. In contrast, contemporary mindfulness does not include "recollections" or "retentions" and instead encourages practitioners to sustain their present awareness without clinging to the past or future. As a result, there are no Buddhist textual descriptions of ethics, judgments, or memories within contemporary mindfulness (Dunne 2015, 254-258).

Contemporary mindfulness is the most cost-effective means to meet the government's objectives regarding children's mental health and to enhance teachers' and parents' well-being. Resilient school-based mindfulness approaches can increase students' learning achievements and overall study behaviors while serving as effective interventions (Sapthiang et al. 2019, 117). Scientifically, regardless of age and level of education, mindfulness practice is considered the most effective, useful, free (or least expensive) method for improving students' focus skills, problem-solving, craving control, interpersonal skills, and emotional stability (Leland et al. 2015, 19-23).

Recently, mindfulness-based intervention programs in the West have been increasing dramatically and helping the 13-14 percent of the youth population who have stress and other mental health issues. For example, in 2019 the United Kingdom began providing a mindfulness program to help youth with their health problems in 370 schools through a large-scale governmental investment, the Anna Freud National Centre for Children and Families. The program will continue through 2021. Similarly, recent research studies, reviews, and meta-analyses about mindfulness-based interventions' (MBI's) efficacy and evidence have increased from 207 published papers in 2014 to 590 papers in 2018 (Emerson et al. 2020 , 62-63). Worldwide, mindfulness and meditational techniques have been increasingly utilized in education because they improve students' cognitive control and academic grades while decreasing behavioral issues, anxiety, depressive symptoms, and attention deficits (Fung 2018, 2).

Regarding the physical benefits for the students, recent evidence indicates that mindfulness-based interventions are feasible and applicable to K-12 students so they can improve their self-discipline, attention spans, and emotional control and reduce their brains' deleterious effects caused by excessive stress. Studies between 2005 and 2009 have found connections between mindfulness training and increased thickness of cortical structures (gray matter) that are related to awareness, working memory, processing sensory input, self-reflection, empathy, and affective regulation (Meiklejohn et al. 2012, 4).

76 2021; 2:1 75-84 The Wabash Center Journal on Teaching

This work is licensed under a Creative Commons Attribution-NonCommercial 4.0 International License 
Another study demonstrates that the decrease of amygdala responses to negative stimuli correlates to the neurocognitive mechanism for stress built through mindfulness training. In particular, students with mental health problems benefit from mindfulness-based training. This, in turn, helps healthy normotensive youth benefit by dealing with their high blood pressure and increased heart rate in relationship to stress, especially among children who are at an increased risk of hypertension (Bauer et al. 2019, 569).

Regarding mental benefits, school-based mindfulness research mainly follows the clinical approaches for adults, and thus these approaches are acceptable and compatible with school-age children, adolescents, and youth (Meiklejohn et al. 2012, 6). In educational settings, while obtaining new knowledge and proficiencies, students can experience stress, anxiety, and depression, all of which may inhibit their learning ability. As a counterpoint, mindfulness practices can enhance students' learning skills and academic achievements through healthier study habits, good planning, higher organizational skills, and better interpersonal aptitudes. Students who practice mindfulness can maintain their focus on their schoolwork, heighten their memories, and support skills specifically for taking the tests successfully.

A University of California at Santa Barbara study showed that mindfulness practices helped students increase their GRE scores by 16 percent (Mrazek 2013, 778). Instead of looking outwardly and competing with others to achieve high scores, mindfulness helps students recognize their own wisdom through inward reflection of views and beliefs while refining their critical thinking to become more astute.

For better behavior and self-control of mental fluctuations, implementing mindfulness practice helps students recalibrate their automatic impulses by teaching new problem-solving skills, proper behaviors, and healthy responses, as well as extending the duration between an impulse and an action. For bullying-related issues, practicing mindfulness can help students improve their behaviors and self-control; resolve classmates' conflicts; instill compassion, tolerance, empathy, and generosity; and increase their courage to speak up and report any incidents. Students with ADHD who practice mindfulness can improve their study habits; reduce impulsive, disruptive, overly physical behaviors and problematic interpersonal skills; and improve their self-control (Leland 2015, 19-23). Mindfulness also provides the skills needed to deal with emotional dysregulation, rumination, and maladaptive perfectionism (Johnson and Wade 2019, 1495). Some studies found that mindfulness-based interventions improve attention span, decision-making function, and social behaviors among children and adults (Quach et al. 2020). Furthermore, many researchers, educators, and therapists have used mindfulness-based intervention to successfully treat children and adolescents suffering from anxiety, pathological concerns, and obsessive-compulsive disorder symptoms.

Psychological flexibility, defined as the ability to be "aware of thoughts and feelings without thought manipulation, changing, and persisting while pursuing an important interest and goals" was developed primarily by mindfulness-based interventions and by acceptance and commitment therapy interventions for children and adolescents (Garcia-Gomez et al. 2019, 1-2).

Research on mindfulness skills programs showed two perceived intrapersonal and interpersonal benefits: self-awareness and self-regulation of cognition, emotions, and behaviors. The development of relationships with family members, friends, and teachers, and learning to trust others are the focal premises of interpersonal benefits (Wisner and Starzee 2016, 245). Evidently, mindfulness training is an effective and cost-efficient way to optimize healthy brain development and function and to enhance stress resilience.

By practicing mindfulness, school-age children can train their minds to concentrate attentively, have internal and external experiences of the present moment objectively and responsively, and have the ability to accept any experience, be it pleasurable, neutral, stressful, or difficult, to improve their curiosity and develop a nonjudgmental mindset.

Regarding social-emotional learning, mindfulness training can help children's awareness, their expression of their emotions, and their moderation of the intensity and duration of emotion-related arousal. This training also helps children self-regulate attention through repeated and intentional focusing, sustaining, and shifting of attention (Meiklejohn et al. 2012, 6). 
Regarding educational benefits, mindfulness-based training can enhance and instill the pedagogy's contemplative education (Cheek et al. 2017, 2565). Specifically, the combination of the direct and indirect school-based mindfulness training provides sustainable benefits to the school community to help students and teachers develop stress-resilient skills and emotional competence (Meiklejohn et al. 2012, 14).

Various research has also experientially supported how mindfulness practice positively impacts the levels of needs, satisfaction, and frustration of college professors, students, and school employees. For example, the need for satisfaction correlates positively with mindfulness practices, but it relates negatively with frustration (Li et al. 2019, 8). Another study demonstrates that in education mindfulness can serve as a promising gateway to the primary psychological need for satisfaction because highly mindful students experienced more satisfaction and less frustration, even when they learned in a low autonomy-supportive teaching environment (Li et al. 2019, 1).

In the past decade, mindfulness-based training in school settings such as Mindfulness-Based Wellness Education (MBWE), Cultivating Awareness and Resilience in Education (CARE), Stress Management and Relaxation Techniques (SMART), and other training in the United States, the United Kingdom, Canada, Israel, and other countries have been implemented in K-12 education to benefit students' and teachers' physical, emotional, and mental well-being. These programs help students improve their attentional skills and ability to deal with psychological and academic challenges, instill pro-social behavior by strengthening self-control and impulse regulation, reduce the destructive stresses that negatively affect learning skills, develop the brain's hygiene skill set, and enhance physical and emotional well-being throughout a lifetime (Meiklejohn et al. 2012, 6).

Other research studies have demonstrated that better grades, better attendance, and higher standardized test scores in math and English language arts related to higher aptitudes for mindfulness. Even at initial stages, those who participated in mindfulness training can prolong their thoughtful and emotional attention, which, in turn, enhances their insights, studying, and self-regulations (Gutierrez et al. 2019, 7).

With sufficient evidence of mindfulness-based intervention, research has shown that by practicing relaxation and mindfulness, adolescents obtain tremendous benefits, such as having substantially enhanced school performance; increasing self-concept, self-efficacy, and social skills; improving information process skills focused more effectively on academic tasks; and decreasing anxiety. In a school context, this intervention was shown to have a significant influence on attention, self-regulation, and aggressiveness. According to teachers' reports about mindfulness interventions, attention problems were reduced sustainably over time. The biggest improvement was the deficit reduction in self-regulation, but it was less sustainable over time than that of attention. Aggressiveness was also reduced significantly (López-Gozález et al. 2016, 122-3, 131).

This study of effective mindfulness-based training in the school context was in line with previous published research. Studies showed that mindfulness-training in school settings can improve students' skills moderately and raise their cognitive performance; diminish their behavioral problems; and positively affect their stress, coping skills, and resilience. Mindfulness training has a greater effect in late adolescence than in the middle of childhood (Suárez-García et al. 2020, 10). Also, students will have significant changes if mindful teachers utilize various combinations of mindfulness techniques (Suárez-García et al. 2020, 10).

In practical terms, Mindfulness-Based Cognitive Therapy-Self Help (MBCT-SH) in a student sample shows its effectiveness as a therapeutic intervention to help students inexpensively deal with mental health difficulties. It reduces anxiety, depression, and stress symptoms while significantly improving life satisfaction, mindfulness, and self-regulation (LeverTaylor et al. 2014, 69).

The Inner Explorer (2020) uses a series of daily five-to-ten-minute audio-guided mindfulness practices that include breathing and relaxation exercises, being aware of the five senses, utilizing thought and emotional regulation, fostering compassion and connection, and advocating social and emotional learning. The Calm Classroom focuses on mindfulnessbased approaches to providing the skills needed to develop a calmer learning environment for students and teachers through self-awareness, mental focus, and emotional resilience (Calm Classroom 2020). Mindful Schools (2020)

78 2021; 2:1 75-84 The Wabash Center Journal on Teaching

This work is licensed under a Creative Commons Attribution-NonCommercial 4.0 International License 
provide educators with practical skills for self-care, facilitation, and connecting with youth through simple and effective mindfulness techniques that can be tailored into school activities and integrated into diverse environments. These meditative techniques are nonsectarian and scientifically proven. In short, teachers can implement these mindfulnessbased interventions to help improve students' academic achievement and well-being.

Disregarding the meditative benefits for educators and students, some critics unfortunately allege it is unconstitutional to offer mindfulness courses in public schools. The American Center for Law and Justice (ACLJ) recently posted some articles that challenge the public schools that offer mindfulness practices (Southerland 2019); for example, the ACLJ alleges that schools using the Inner Explorer (2020) violate the law because they used public funds to instill Buddhist principles (Southerland 2019).

Founded by minister and televangelist Pat Robertson in 1990 (along with chief counsel Jay Sekulow, who is President Trump's personal lawyer), the American Center for Law and Justice (ACLJ) collected more than 85,000 signatures to promote "Stop Forcing Buddhist Meditation on Kids in School" in late 2018. However, legal experts and mindfulness educators felt confident that the opposition to mindfulness in schools would not reach the Supreme Court. Moreover, Tricycle magazine raised concerns about future challenges for these advocates (Agasar 2020). Despite no clear legal strategy for defending mindfulness-based training, it still spread across US school districts like wildfire as teachers and administrators progressively utilized it to reduce stress, improve productivity, and cultivate social and emotional skills in students, teachers, and administrators.

The US Department of Health and Human Services statistically enumerated the substantial rise in children's participation in mindfulness practices from 0.6 percent in 2012 to 5.4 percent in 2017 (NIH 2017). Legally, the First Amendment allows religious expression such as a prayer before government meetings, Bible study after school, et cetera. Since 1970, however, a three-pronged approach (the Lemon Test) has been used by the court to determine any violation in the First Amendment, any obvious evidence of religious purpose and effect, and any governmental involvement in religious affairsrelated decisions.

Since yoga has been stripped of all religious references, it is now permissible to teach it in public schools, based on recent court decisions. According to Susan Kaiser Greenland, a longtime mindfulness educator and a former lawyer, due to the scale, underfunding, and lack of a legal strategy, the use of mindfulness in education community is not ready to make a coordinated response to challenges, especially those posed by well-funded individuals and organizations as in the case of Sedlock v. Baird (2013) in San Diego (Agasar 2020). In the mindfulness-in-schools community, there is no clear leader or "coordinated, big picture effort" in place to deal with court cases or future challenges. Greenland proposes to form an independent organization to develop unity between the community and skeptics and to work on coordinated legal responses. She is concerned about how to teach mindfulness with religious neutrality and in children's best interest, as well as how to manage trauma properly and provide practices that are age appropriate (Agasar 2020).

Shannon Pitcher-Boyea, a former principal and a certified yoga and mindfulness teacher, as well as a member of the International Mindfulness Teachers Association (IMTA), warns about the accidental line crossing between religious neutrality and religious implications when schools allow enthusiastic educators to teach mindfulness as an effective way to deal with societal pressures, stresses, bullying, and other school-related problems. While working with school districts, Pitcher-Boyea provides a sample letter for staff to let the parents know clearly about the mindfulness program with a chance to opt out (Agasar 2020).

In her book, Debating Yoga and Mindfulness in Public Schools (2019), Candy Gunther Brown, a religious studies professor who has testified several times in courts about the religious roots of yoga and mindfulness, insists that taking out religious references will not separate those practices from their religious origins. As a result, Pitcher-Boyea advocates that school staffs and teachers should be trained properly on civil liberties and in teaching mindfulness in schools (Agasar 2020).

Laura Bakosh, a longtime Mindfulness-Based Stress Reduction (MBSR) practitioner (and cofounder of Inner Explorer [2020] which provides pre-recorded audio mindfulness programs that are used in three thousand schools), mentioned that the ACLJ has failed to stop any mindfulness program across the country. Its challenges have mainly reinforced organizations' 
secular stance by using narrative flexibility in teaching mindfulness practices. Her primary concern is not how to respond the complaints or how to make a strategy for the future, but the disparities between the descriptions and understanding of mindfulness. She also mentioned that after more than four decades of scientific evidence, many health professionals and professors, even at Christian colleges across the country, are utilizing mindfulness as an effective and inexpensive tool to solve the major issues of stress, anxiety, and suicidal ideation. The ACLJ challenges serve to bring awareness about the availability of mindfulness to enhance children's success, and that is positive (Agasar 2020).

In general, children should be educated about the various religious roles in society and the world and not be indoctrinated by certain religious traditions (Evans 2008, 449). To do this, the Religious Freedom Restoration Act (RFRA) affirms extensive safeguards for people of every religion. Thirty-five religious and civil liberties organizations advocated for students' religious rights in public school, including the right to pray, discuss their religious views, form religious clubs, access to school facilities under the Equal Access Act, distribute religious literature, and take religious courses ("The Bible and Public Schools").

Contrarily, for many decades, Christians have been pushing successfully for teaching Bible courses in the public schools. For instance, the president of the National Council on Bible Curriculum in Public Schools proudly boasts that 93 percent of school boards in forty-one states with 3,274 high schools are offering Bible courses in various ways to more than 650,000 students (NCBCPS 2019). To date, press releases mention only six states passing laws to teach the Bible in public schools. For example, Kentucky House Bill 128 makes teaching Bible courses in Kentucky's public schools legal (KY HB128/2017/ Regular Session).

Greg Abbott, then the Attorney General of Texas, gave school districts there the option to teach Bible courses (Abbott 2008). In Texas during the school year of 2011-12, fifty-seven school districts and three charter schools offered Bible courses or incorporated them into other subjects such as English, social studies, and general electives, and student enrollment ranged from one to fifty (Chancey 2013, 14, 17).

Chancey pointed out that several Texas Bible courses used prevalent public sources and non-academic Bible supplemental sources that target churchgoers' children and strengthen their faith $(2013,13)$. For instance, Dalhart ISD used a book produced by a biblical apologetic organization to promote that God is perfect, infallible, holy, pure, omniscient, omnipotent, and omnipresent (Chancey 2013, 28). Four school districts used fictional movies to strengthen Christian faith and evangelize non-Christians (Chancey 2013, 19).

Chancey also reported that Dayton ISD used Gene Taylor's The Gospel of John: Evidences for Belief (2005). The Preface defines the author's goals clearly: "May this study be of value to you. May you fully come to believe that "Jesus is the Christ, the son of God.' And may you have 'life in His name”' (Chancey 2013, 18).

The ACLU of Kentucky recently sent a complaint regarding the “Bible Literacy” courses offered in some of Kentucky's public schools, which adapted lessons and exercises explicitly and directly from online courses used in Sunday schools, as well as required students to memorize passages directly from the Bible (ACLU 2018). Teaching Bible courses in public schools can strengthen the Christian faith, promote a perfect good, and encourage a belief in Jesus. However, it is rare to find research studies showing that Bible study improves students' learning skills, achievement, classroom behavior, and so forth, except some studies which confirm that spirituality, regardless of the religion, may generally improve the adherents' mental well-being (Wall 2012). On the other hand, almost one million children used meditation every day in 2017 because of its tremendous benefits (Black et al. 2015, 9).

As stated previously, the Inner Explorer (2020), Calm Classroom (2020), and Mindful Schools (2020) promote self-help, self-awareness, and self-regulation to enhance students' well-being and development. Yet, the ACLJ led by Jay Sekulow opposed the use of mindfulness in schools on his radio program and collected more than 80,000 signatures on an evangelical website in December 2018 (Hignett 2018). Paradoxically, in August of 2019, the ACLJ celebrated Supreme Court's decision to reject a lawsuit to have 'In God We Trust' removed from our national currency while fighting to preserve the secularity of public spaces from mindfulness and yoga practices to preserve Christian influence over American culture (Helderman 2019). 
An unfair discrepancy exists between how nonsectarian mindfulness practices with their rarely mentioned Buddhist expressions as promoted by the Inner Explorer and other mindfulness-based enterprises are branded and condemned as "Buddhist indoctrination," whereas Judeo-Christian teachings of Bible courses easily and explicitly slip into US public education as stated above.

In conclusion, since almost one million children used meditation in 2017 due to its effectiveness and improvement of achievement, study skills, behaviors, self-regulations, and so forth, public school students should have the legitimate right to learn and practice meditation in a nonsectarian way and in accordance with academic standards. Also, by comparing how the school districts in six states preferentially teach Bible courses directly and explicitly to their respective students while those offering mindfulness courses (like Mind Up [2020], Inner Explorer [2020], Calm Classroom [2020], and Mindful Schools [2020]) without claiming any Buddhist connection are protested, there are some degrees of unfairness and discrepancy religiously and constitutionally.

As a result, since several states have allowed teaching Bible courses as part of religious education, per religious rights and liberties, any public school that allows the teaching of Bible courses should offer other religious studies as well, such as Buddhism and Hinduism, because parents of all religions pay taxes for funding public schools. Furthermore, by studying Eastern traditions such as Buddhism and Hinduism, students will broaden their knowledge and be better prepared global citizens.

\section{B IBLIOGRAPHY}

Abbott, Greg. 2008. Opinion No. GA-0657. August 08. https://www2.texasattorneygeneral.gov/opinions/ opinions/50abbott/op/2008/pdf/ga0657.pdf.

ACLJ. 2018. "Stop Forcing Buddhist Meditation on Kids in School.” Washington, DC: The American Center for Law and Justice. https://aclj.org/religious-liberty/stop-forcing-buddhist-meditation-on-kids-in-school.

ACLU. 2018. “ACLU-KY Reviews ‘Bible Literacy’ Courses in Kentucky Public Schools: Open Records Act Investigation Finds Serious Fundamental and Constitutional Issues.” ACLU. January 8. https://www.aclu.org/press-releases/ aclu-ky-reviews-bible-literacy-courses-kentucky-public-schools.

Agasar, Wendy Joan Biddlecombe. 2020. “Mindfulness in Schools, Revisited.” Tricycle, Spring. https://tricycle.org/ magazine/school-meditation-revisited/.

Bauer, Clemens C.C., et al. 2019. "Mindfulness Training Reduces Stress and Amygdala Reactivity to Fearful Faces in Middle-School Children.” Behavioral Neuroscience 133, no. 6: 569-585.

Black, Lindsey et al. 2015. "Use of Complementary Health Approaches Among Children Aged 4-17 Years in the United States: National Health Interview Survey, 2007-2012.” Natl Health Stat Report. 2015 February 10; (78): 1-19.

Braboszcz, Claire, and Arnaud Delorme. 2010. "Chapter 27, Meditation and Neuroscience: From Basic Research to Clinical Practice." Integrative Clinical Psychology, Psychiatry and Behavioral Medicine: Perspectives, Practices and Research. 1910-1925.

Brown, Candy Gunther. 2019. Debating Yoga and Mindfulness in Public Schools. Chapel Hill, NC: University of North Carolina Press.

Calm Classroom. 2020. Calm Classroom. https://calmclassroom.com/.

Chancey, Mark. 2013. Reading, Writing and Religion II: Texas Public School Bible Courses in 2011-12. Austin, TX: Texas Freedom Network Education Fund. https://www.smu.edu/-/media/Images/News/PDFs/Mark-Chancey-ReadingWriting-Religion-study.pdf?la=en. 
Cheek, Julianne, et al. 2017. "Creating Novel School-Based Education Programs to Cultivate Mindfulness in Youth: What the Letters Told Us." Journal of Children and Family Study 26: 2564-2578.

Dunne, John D. 2015. "Buddhist Styles of Mindfulness: A Heuristic Approach.” In Handbook of Mindfulness and SelfRegulation, edited by Brian D. Ostafin, Michael D. Robinson, and Brian P. Meier, 251-270. New York, NY: Springer.

Emerson, Lisa-Marie, et al. 2020. “Mindfulness Interventions in Schools: Integrity and Feasibility of Implementation.” International Journal of Behavioral Development 44, no. 1: 62-75.

Evans, Carolyn. 2008. "Religious Education in Public Schools: An International Human Rights Perspective.” Human Rights Law Review 8, no. 3: 449-473.

Fung, Joey. 2018. "A Randomized Trial Evaluating School-Based Mindfulness Intervention for Ethnic Minority Youth: Exploring Mediators and Moderators." Journal of Abnormal Child Psychology 47: 1-19.

Garcia-Gómez, Maria, et al. 2019. “Cognitive Fusion Mediates the Relationship between Dispositional Mindfulness and Negative Affects: A Study in a Sample of Spanish Children and Adolescent School Students." International Journal of Environmental Research and Public Health 16, no. 23: 4687.

Gutierrez, Akira S., et al. 2019. Mindfulness in the Classroom: Learning from a School-based Mindfulness Intervention through the Boston Charter Research Collaborative. Boston, MA: Harvard University, Center for Education Policy Research, Transforming Education.

Helderman, Ira. 2019. "The Crusade Against Mindfulness: The debate over where mindfulness practices are religious is now in the courts." Psychology Today, 06 Sept. https://www.psychologytodav.com/us/blog/therapv-andbuddhist-traditions/201909/the-crusade-against-mindfulness.

Hignett, Katherine. 2018. “Conservative Christians Want to Stop Kids Meditating at School.” Newsweek, December 15. https://www.newsweek.com/mindfulness-meditation-schools-aclj-buddhism-1260323.

Inner Explorer. 2020. Daily Mindfulness Practice: Simplified. https://innerexplorer.org/.

Johnson, Catherine, and Tracey Wade. 2019. "Piloting a More Intensive 8-Week Mindfulness Programme In Early- and Mid-Adolescent School Students.” Early Intervention in Psychiatry 13, no. 3: 1495-1502.

Leland, Matt. 2015. “Mindfulness and Student Success.” Journal of Adult Education 44, no. 1: 19-23.

Lever-Taylor, B., et al. 2014. "The Effectiveness of Self-Help Mindfulness-Based Cognitive Therapy in a Student Sample: A Randomized Controlled Trial." Behavior Research and Therapy 63: 63-69.

Li, Chunxiao, et al. 2019. "Autonomy-Supportive Teaching and Basic Psychological Need Satisfaction among School Students: The Role of Mindfulness." International Journal of Environmental Research and Public Health 16, no. 14: 2599.

López-González, Luís, et al. 2016. “Habits Related to Relaxation and Mindfulness of High School Students: Influence on Classroom Climate and Academic Performance.” Revista de Psicodidactica 21, no. 1: 122-138.

Meiklejohn, John, et al. 2012. "Integrating Mindfulness Training into K-12 Education: Fostering the Resilience of Teachers and Students." Mindfulness 3: 291-307.

Mind Up. 2020. Mind Up. https://mindup.org/.

Mindful Schools. 2020. Mindful Schools. https://www.mindfulschools.org/. 
Mrazek MD, Franklin MS, Phillips DT, Baird B, Schooler JW. 2013. “Mindfulness training improves working memory capacity and GRE performance while reducing mind wandering." Psychol Sci. May, 24(5):776-81. doi: $10.1177 / 0956797612459659$.

NCBCPS (National Council on Bible Curriculum in Public Schools). 2019. "Where This Has Been Implemented." National Council on Bible Curriculum in Public Schools. http://www.bibleinschools.net/Where-This-Has-BeenImplemented.php.

NIH. 2017. National Health Interview Survey. Bethesda, MD: National Institutes of Health. https://www.nccih.nih.gov/ research/statistics/nhis/2017.

Quach JL., et al. 2020. "Can a Teacher-Led Mindfulness Intervention for New School Entrants Improve Child Outcome? Protocol for a School Cluster Randomized Controlled Trial." BMJ Open 10, no. 5.

Richards, Erin. 2019. “Bible Classes in Public Schools?” USA Today, January 23. https://www.usatoday.com/story/ news/education/2019/01/23/in-god-we-trust-bible-public-school-christian-lawmakers/2614567002/.

Ruhe, Brian. 2005. Freeing the Buddha: Diversity on a Sacred Path-Large Scale Concerns: A Course on Major Aspects of Buddhism Plus a Dangerous Collection of Essays. Delhi, India: Motilal Banarsidass Publishers.

Sapthiang, Supakyada et al. 2019. "Mindfulness in Schools: A Health Promotion Approach to Improving Adolescent Mental Health.” International Journal of Mental Health and Addiction 17: 112-119.

Southerland, Abigail A. 2019. "Buddhist Indoctrination Updates: Achieving Victories as We Expose the Intent Behind 'Mindfulness' Program in Public Schools.” ACLJ.org, March. American Center for Law and Justice: Washington D.C. https://aclj.org/religious-liberty/buddhist-indoctrination-update-achieving-victories-as-we-expose-the-intentbehind-mindfulness-programs-in-public-schools.

Suárez-García, Zara, et al. 2020. "The Effect of a Mindfulness-Based Intervention on Attention, Self Control, and Aggressiveness in Primary School Pupils.” International Journal of Environmental Research and Public Health 17 , no. 7: 2447 .

Taylor, Gene. 2005. The Gospel of John: Evidences for Belief. Self-published. https://www.padfield.com/acrobat/ taylor/john-gospel.pdf.

Wall, Tim. "Spirituality Correlates to Better Mental Health Regardless of Religion, Say MU Researchers." University of Missouri, News Bureau, 20 Aug. 2012. https://munewsarchives.missouri.edu/newsreleases/2012/0820-spirituality-correlates-to-better-mental-health-regardless-of-religion-say-muresearchers/\#: :text=Spirituality\%20Correlates\%20to\%20Better\%20Mental\%20Health\%20Regardless\%20 of $\% 20$ Religion $\% 2$ C $\% 20$ Say $\% 20$ MU\%20Researchers,-August $\% 2020$ th\%2C $\% 202012$ \&text=COLUMBIA $\% 2$ C $\% 20$ Mo.,to\%20University\%200f\%20Missouri\%20researchers.

Weaver, K.D. 2018. Meditate Like Jesus: Uncover the Meditative Practices of Jesus. Eugene, OR: Wipf and Stock Publishers.

Wisner, Betsy L., and James J. Starzec. 2016. "The Process of Personal Transformation for Adolescents Practicing Mindfulness Skills in an Alternative School Setting." Child Adolescent Social Work Journal 33: 245-257.

\section{ABOUT THE AUTHOR}

Trung Huynh (Thich Hang Dat) is Professor of Religious Studies at the University of Houston, Indiana University Southeast, Indiana University South Bend, and Indiana University Kokomo. He specializes in Buddhist Education with research focus on religious equality, Zen Buddhism, and early Vietnamese Buddhism. 
